Pteridines

Vol. 9, 1998, pp. $18-21$

\title{
Purification and Characterization of Sepiapterin Deaminase from the Silkworm, Bombyx mori*
}

\author{
Hiroshi Sawada $^{1 \S}$, Motoki Kanekatsu ${ }^{1}$, Motoko Nakagoshi ${ }^{1}$, Kenjiro Dohke ${ }^{1}$, Teruhiko Iino ${ }^{2}$ \\ and Shin-Ichiro Takikawa ${ }^{1}$ \\ ${ }^{1}$ Biological Laboratory, Center of Liberal Arts and Sciences, Kitasato University, Kitasato 1-15-1, \\ Sagamihara city, Kanagawa 228, Japan \\ ${ }^{2}$ Department of General Education, Nihon University, Sakurajosui 3-25-40, Setagaya-ku, \\ Tokyo 156, Japan
}

(Received September 11, 1997)

\begin{abstract}
Summary
Sepiapterin deaminase has been purified approximately 6,000-fold from the larval integument of the lemon mutant of the silkworm by several column chromatographic procedures. Sepiapterin and isosepiapterin were active substrates among various pteridines tested. The molecular mass of this enzyme was estimated to be $74 \mathrm{kDa}$ by SDS-PAGE and $70 \mathrm{kDa}$ by gel filtration, suggesting that the native form of the enzyme is monomeric protein. All silkworm strains, to the best of our knowledge, had an activity of the enzyme and the enzyme was widely distributed in the larval tissues. Sepiapterin deaminase may have an important function on the silkworm.
\end{abstract}

Key words : Sepiapterin deaminase, Silkworm

\section{Introduction}

Sepiapterin deaminase (EC 3.5.4.24) catalyzes the hydrolytic deamination of sepiapterin to form sepialumazine. The enzyme was first found in the lemon mutant of the silkworm, Bombyx mori (1) and its properties were also described (2). The yellow larval colour of the mutant lemon is due to sepiapterin and sepialumazine (3). Sepiapterin itself has not been detected in any other strains except the lemon mutant. In contrast, sepialumazine is widely distributed in many strains of silkworm (4). The light yellow color of the mutant Kiuki lar-

\$ Author to whom correspondence should be addressed.

* Parts of the work have been presented at the 4th Meeting of Cytokine and Neopterin held on July 19, 1997, in Tokyo, Japan. vae is due to the accumulation of a greater amount of sepialumazine than in any other strains (5). In the case of the Kiuki larval integument, the sepialumazine content and activity of sepiapterin deaminase showed peaks at the end of the final instar stage. Thereafter a large decrease in the pigment and the enzyme activity were found during the spinning stage (6). Takikawa et al. revealed that all silkworm strains, to the best of their knowledge, had an activity of sepiapterin deaminase and the enzyme consisted of isozymes (7). This result, together with the wide distribution of the enzyme (2), suggests that the enzyme is indispensable for the silkworm. Sepiapterin deaminase may have an important function in addition to the regulation of larval colour.

In order to investigate other possible functions

Pteridines $/$ Vol. $9 /$ No. 1 
of sepiapterin deaminase, we attempted to highly purify the enzyme from the lemon mutant of the silkworm.

\section{Materials and Methods}

\section{Experimental animals}

Lemon mutant larvae of the silkworm, Bombyx mori, were reared routinely on mulberry leaves at $25^{\circ} \mathrm{C}$. On the 4 th day of the 5 th instar, the larvae were dissected with scissors and washed quickly with water. The integument was separated from the other tissues and stored at $-80^{\circ} \mathrm{C}$ until use.

\section{Chemicals}

Sepiapterin was purchased from Dr. Schircks Laboratories (Jona, Switzerland) and was further purified by the method of Sugiura et al. (8). Sepialumazine was synthesized enzymatically (2). Other pteridines were kind gifts from Prof. Matsuura of Fujita Health University College.

\section{Sepiapterin deaminase assay and gel electrophoresis}

Sepiapterin deaminase was assayed by high performance liquid chromatography (HPLC) as previously described (9). Sodium dodecyl sulfate-polyacrylamide gel electrophoresis (SDS-PAGE) was performed using $12.5 \%$ polyacrylamide gel in a discontinuous tris-glycine buffer system as described by Laemmli (10). The gel were stained with Copper Stain \& Destain Kit (Bio-Rad).

\section{Results and Discussion}

\section{Purification of sepiapterin deaminase}

The enzyme was purified by the method of Tsusué (2) with slight modification. Frozen integument was thawed, cut into small pieces with scissors and homogenized in a Waring blender with 4 volumes of $0.05 \mathrm{M}$ potassium phosphate buffer (PPB), $\mathrm{pH} 6.5$, for $4 \mathrm{~min}$. The homogenate was centrifuged at $8,000 \times \mathrm{g}$ for $20 \mathrm{~min}$. The resulting supernatant was collected after filtration to remove fat. The precipitate after centrifugation was rehomogenized and centrifuged in the same way. The supernatant was collected and combined with the first extract. Solid ammonium sulfate was added to the supernatant solution to give $50 \%$ saturation, the mixture was stirred for 60 min. The precipitate was removed by centri- fugation at $8,000 \times \mathrm{g}$ for $20 \mathrm{~min}$. Additional solid ammonium sulfate was added to give $75 \%$ saturation. The precipitated proteins were collected by centrifugation at $8,000 \times \mathrm{g}$ for $20 \mathrm{~min}$ and dissolved in a small amount of $0.05 \mathrm{M}$ PPB, $\mathrm{pH} 7.0$, and dialyzed overnight against the same buffer. The dialyzed solution was centrifuged at $8,000 \times$ $\mathrm{g}$ for $20 \mathrm{~min}$ and the supernatant solution was applied to a column of DEAE-cellulose equilibrated with $0.05 \mathrm{M} \mathrm{PPB}, \mathrm{pH}$ 7.0. After washing the column with the same buffer, elution was carried out with a linear gradient of $0-0.5 \mathrm{M} \mathrm{NaCl}$ in the same buffer. The enzyme solution from DEAEcellulose column was applied directly to a hydroxyapatite column, equilibrated with $0.02 \mathrm{M}$ $\mathrm{PPB}, \mathrm{pH}$ 8.0. After washing the column with the same buffer, elution was carried out with a linear gradient of 0.02-0.5 M PPB, pH 8.0. The enzyme solution from the hydroxyapatite column was concentrated to about $3 \mathrm{ml}$ and applied to a Superdex column equilibrated with PPB containing $0.5 \mathrm{M} \mathrm{NaCl}$. The enzyme solution from the Superdex column was dialyzed overnight against PPB and concentrated to about $3 \mathrm{ml}$. The concentrated solution was applied to a Mono $Q$ column equilibrated with PPB, elution was carried out with a linear gradient of $0-0.7 \mathrm{M} \mathrm{NaCl}$ in the same buffer. The elution profile is shown in Figure 1 . Fractions 18 and 19 had enzyme activity.

Table 1 represents a summary of the purification of sepiapterin deaminase from the integument of the lemon mutant larvae of the silkworm.

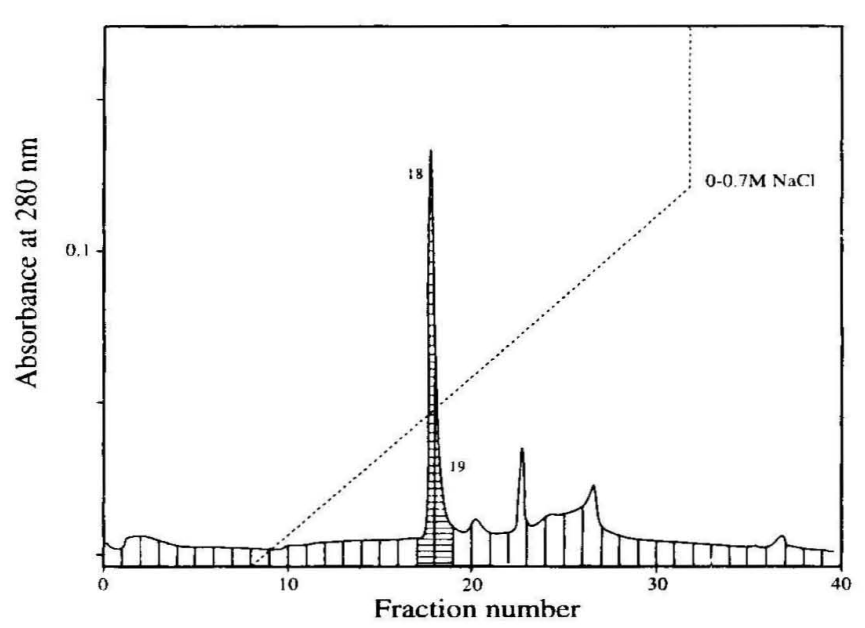

Figure 1. Elution profile of sepiapterin deaminase from a Mono $Q$ column. Proteins were eluted with a linear gradient to $0-0.7 \mathrm{M} \mathrm{NaCl}$ in $\mathrm{PPB}$ at a flow rate of $1 \mathrm{ml} /$ min and monitored absorbance at $280 \mathrm{~nm}(-)$. The lateral stripes area, fractions 18 and 19 , indicates the fraction containing the enzyme activity. 
Table 1. Summary of purification of sepiapterin deaminase

\begin{tabular}{lcccrr}
\hline \hline & $\begin{array}{c}\text { Volume } \\
(\mathrm{ml})\end{array}$ & $\begin{array}{c}\text { Total } \\
\text { protein }(\mathrm{mg})\end{array}$ & $\begin{array}{c}\text { Total } \\
\text { activity }\left(\times 10^{9}\right)\end{array}$ & $\begin{array}{c}\text { Specific } \\
\text { activity }\end{array}$ & $\begin{array}{c}\text { Yield } \\
(\%)\end{array}$ \\
\hline Crude extract & 240 & 394 & 7.42 & 1.0 & 100 \\
Ammonium sulfate & 18.2 & 69.4 & 9.68 & 7.4 & 130 \\
DEAE-cellulose & 10.5 & 7.00 & 8.02 & 60.8 & 108 \\
Hydroxyapatite & 6.3 & 1.13 & 7.31 & 342 & 98.5 \\
Superdex & 6.0 & 0.22 & 5.42 & 1320 & 73.0 \\
Mono Q & 2.0 & 0.03 & 3.40 & 5960 & 45.8 \\
\hline
\end{tabular}

By this procedure the enzyme was purified approximately 6,000 -fold. The fact that the yield in the ammonium sulfate step is over $100 \%$ probably indicates the elimination of some inhibitors.

\section{Substrate specificity}

Tsusué (2) reported that the enzyme had rather high substrate specificity and utilizes only sepiapterin and isosepiapterin as the substrates. In this study, the following pteridines are inactive as the substrate: 7-hydroxybiopterin, L-erythro-neopterin, L-threo-neopterin, D-erythro-neopterin, D-threoneopterin, L-erythro-biopterin, L-threo-biopterin, D-erythro-biopterin, D-threo-biopterin, dihydroneopterin, dihydrobiopterin and tetrahydrobiopterin. These results suggest that sepiapterin deaminase may not be regulated by the biosynthesis of tetrahydrobiopterin.

\section{Determination of molecular weight by SDS-PAGE}

When the purified enzyme from a Mono Q column, fractions 18 and 19 , were analyzed by SDS-PAGE, one major protein band and two mi-

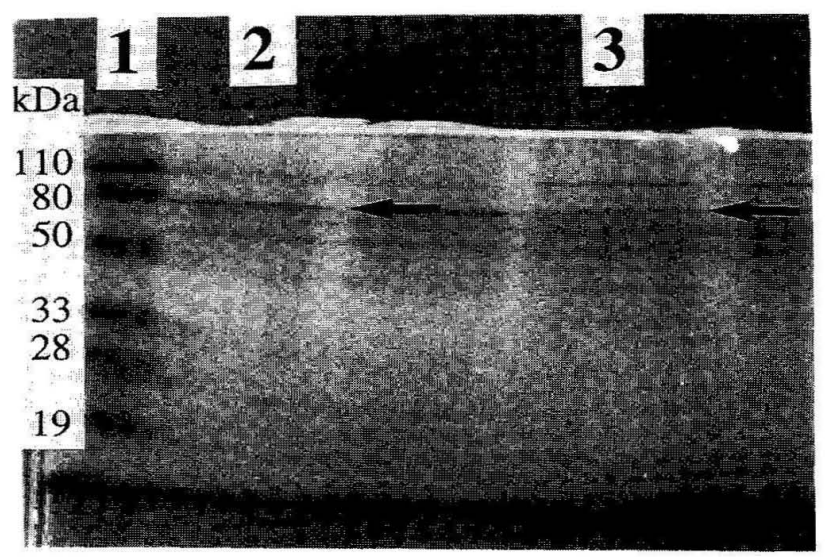

Figure 2. SDS-PAGE of the final purification step of sepiapterin deaminase from the integument of the lemon mutant larvae of the silkworm. Lane 1 contains molecular weight marker proteins. Lane 2 and 3 show the proteins in fractions 18 and 19 from a Mono $Q$ column, respectively. The arrows show sepiapterin deaminase. nor bands were observed (Figure 2). Then the proteins were extracted from the polyacrylamide gel after SDS-PAGE and dialyzed overnight against PPB. The dialyzed solution was subjected to the enzyme assay, sepiapterin deaminase activity corresponded to the main protein band (arrows of Figure 2). Other minor protein bands did not affect sepialumazine formation.

The molecular weight of sepiapterin deaminase was estimated to be $74 \mathrm{kDa}$ by SDS-PAGE (Figure 3). Takikawa et al. (6) also reported that the molecular weight of the enzyme was $70 \mathrm{kDa}$ using gel filtration (Toyo Pearl HW $50 \mathrm{~S}$ ). These results indicate that the native form of sepiapterin deaminase is a $74 \mathrm{kDa}$ and monomeric protein. Further studies on the primary structure of the enzyme are now being undertaken.

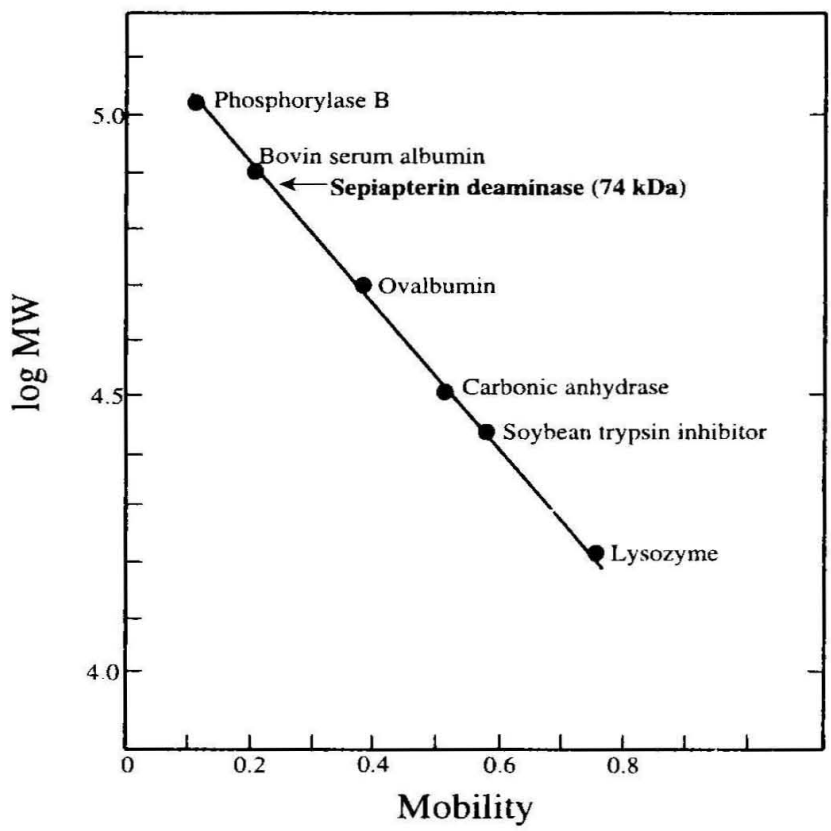

Figure 3. Molecular weight determination of sepiapterin deaminase by SDS-PAGE. The molecurar weight marker proteins were: lysozyme $(19 \mathrm{kDa})$, soybean trypsin inhibitor $(28 \mathrm{kDa})$, carbonic anhydrase $(33 \mathrm{kDa})$, ovalbu$\min (50 \mathrm{kDa})$, bovine serum albumin $(80 \mathrm{kDa})$, phosphorylase $\mathrm{B}(110 \mathrm{kDa})$. The arrow shows sepiapterin deaminase. 


\section{Acknowledgment}

We thank Dr. Keisuke Mase and Dr. Toshio Yamamoto of the National Institute of Sericultural and Entomological Science for their kind provision of silkworms.

\section{References}

I. Tsusué M. Occurrence of sepiapterin deaminase in the silkworm, Bombyx mori. Experientia 1967; 23 . 116-119.

2. Tsusué M. Studies on sepiapterin deaminase from the silkworm, Bombyx mori. J. Biochem. 1971; 69: 781-788.

3. Tsusué $M$. and Akin $M$. Yellow pterins in mutant lemon of silkworm and mutant sepia of $D$. melanogaster. Zool. Mag. 1965; 74: 91-94.

4. Ohashi M, Tsusué M, Yoshitake N, Sakate S, Kiguchi K. Epidermal pigments affecting the larval colouration of the silkworm, Bombyx mori. J. Seric. Sci. Jpn. 1983; 52: 498-504.
5. Mazda T, Tsusué M, Sakate S. Purification and identification of a yellow pteridine characteristic of the larval colour of the Kiuki mutant of the silkworm, Bombyx mori. Insect Biochem. 1980; 10: 357-362.

6. Tsusué M, Mazda T, Sakate S. Studies on sepialumazine, the characteristic larval integument pigment of the Bombyx mori Kiuki mutant. In: Blair JA, ed. Chemistry and Biology of Pteridines. Berlin-New York: Walter de Gruyter, 1983; 675-679.

7. Takikawa $S$, Tsusué $M$, Yamamoto T. Activity stain method for sepiapterin deaminase in the silkworm. J. Seric. Sci. Jpn 1987; 56: 235-239.

8. Sugiura $K$, Takikawa $S$, Tsusué $M$, Goto $M$. Isolation and characterization of a yellow pteridine from Drosophila melanogaster mutant sepia. Bull. Chem. Soc. Japan 1973; 46: 3312-3313.

9. Tsusué M, Kuroda S, Sawada H. Localization of sepiapterin deaminase and pteridines in the granules in epidermal cells of the silkworm, Bombyx mori. Pteridines 1990; 2: 175-182.

10. Laemmli U. K. Cleavage of structural proteins during the assembly of the head of bacteriophage T4. Nature 1970; 227: 680-685. 